Dept. for Speech, Music and Hearing Quarterly Progress and Status Report

\title{
Measurements of the vibrato rate of ten singers
}

\author{
Prame, E.
}

journal: STL-QPSR

volume: 33

number: 4

year: 1992

pages: $\quad$ 073-086 



\title{
MEASUREMENTS OF THE VIBRATO RATE OF TEN SINGERS
}

\author{
Eric Prame
}

\begin{abstract}
The vibrato rate for ten singers, all singing Schubert's Ave Maria, was measured on sonograms. Commercially available $C D$ records were used to insure that the vibrato originated in a real musical performance. It was found, that the vibrato rate typically increased at the end of each tone, while no typical structure could be found in the beginning of a tone. Disregarding the increase of vibrato rate toward tone endings, the mean rate across singers was $6.1 \mathrm{~Hz}$. The average variation between maximum and minimum rate within an artist is about $\pm 10 \%$ of the artist average. The variation across artists between the maximum and minimum personal mean rate was also about $\pm 10 \%$ of the group average.
\end{abstract}

\section{INTRODUCTION}

Carl E. Seashore and his many co-workers at the Iowa University carried out a true pioneering work, when they in the late 20th and the early 30th studied all aspects of the at that time unexplored vibrato. Their main emphasis was laid on the vocal vibrato. They designed ingenious instruments for analysis and the knowledge that they collected is - strangely enough - still largely accepted as the basis. They have published their findings extensively in a great number of articles and books (see Seashore $1932 ; 1936 ; 1937 ; 1938$ ).

After Seashore, the research changed from the massive effort to small studies concentrating on one or a few facets of vibrato. Shipp, Leanderson, \& Sundberg (1980) describe the situation in this way: "Since the monumental work of Seashore 1932, few acoustic investigations of vocal vibrato have appeared in the scientific literature." Also the experimental conditions changed completely: "Much of Seashore's studies analyzed singers performing a musical work, whereas contemporary studies had subjects sustaining a vowel sound on a designated pitch. Further, contemporary singer subjects were recorded in heavily sound-treated rooms affording little or no reverberation, which may also have affected vibrato rate." (Hakes, Shipp, \& Doherty, 1987).

During the last decades, many authors have complained about the discrepancies of published figures on vibrato rate (e.g., Shipp, \& al., 1980; Hakes, \& al., 1987, Horii 1989). Also discussions of the vibrato, especially those of a physiological nature, have suffered from the wageness of the vibrato rate figures. If one wanted to relate the vibrato rate to other periodic phenomena in the human body, one was pursuing a difficult task.

Physically the vibrato produced by Western opera singers corresponds to a modulation of the voice fundamental frequency (Horii, 1989). As a secondary effect, a timbral vibrato is produced corresponding to a modulation of the levels of the spectrum partials. This modulation arises as the partials are modulated by the vocal tract resonances, i.e., the formants (Sundberg, 1982; Horii, 1989; Meyer, 1991). The amplitude modulation of the partials results in a modulation of the overall sound level. A phenomenon which possibly could produce an autonomous timbral vibrato was hypothesized by Sundberg (1987), and corroborated by Rothenberg, Miller, \& 
Molitor (1988). Phenomena producing an autonomous intensity vibrato, appearing along with the frequency vibrato, were mentioned by Shipp, Sundberg, \& Haglund (1984) and Shipp. Doherty, \& Haglund (1990).

The present investigation was only concentrated on the frequency modulation aspects of vocal vibrato. Seashore's method of using material recorded in a real musical context was resorted to. We expect that the findings documented in this article will resolve the above-mentioned confusion, thus increasing the possibilities of a thorough, scientific understanding of the vibrato.

\section{MEASUREMENTS}

\section{The vocal vibrato}

The frequency modulation underlying a vibrato has three major characteristics: its rate, its extent, and its waveform. The focus of this study is the vibrato rate, while the extent and waveform will be analyzed in forthcoming studies.

Two aspects of the vibrato rate of a tone can be analyzed :

- the intra-tone aspect, showing measurements of the inverse of vibrato cycle duration within a tone; such data produce curves showing how the vibrato rate changes during the course of a tone.

- the inter-tone aspect, showing how the average vibrato rate for the individual tones changes during a piece of music.

Of course, also the artist is an interesting factor: both the intra-artist variation of the vibrato rate and the inter-artist variation of the vibrato rate.

\section{Material}

The aim of the present investigation was to gain a description of vibrato rate variability in a musical context. For the analysis, we selected the vibrato that is used by prominent artists of our time, educated in the Western classical music tradition. Real musical performances were preferred to phonations of selected tones produced in a laboratory setting because of the risk of obtaining artefacts due to the selection of phonations, as well as the possible influence of the laboratory environment.

The material was further restricted to commercially available $C D$ records. This implies that no usable measurements can be made of SPL or vocal loudness. On the other hand, this selection had the significant advantage that a great number of artists of world class could serve as subjects at a minimum of costs and inconvenience.

An efficient comparison of different artists' vibrato requires that a piece of music is selected which

- has been recorded by many artists,

- is typically sung with a great vibrato extent,

- is typically sung in a rather slow tempo, thus providing a great number of vibrato cycles, and

- $\quad$ has been recorded also with string instruments for comparison.

Taking the above requirements into considerations we chose Ave Maria by Franz Schubert (Fig. 1). Records of 13 different singers were initially selected, and ten of these were selected for analysis, as they turned out to provide the best conditions for vibrato measurements (Table I). In these recordings, the accompaniment was performed on different instruments; normally, harp and piano do not disturb the measurements of the solo voice to any great extent while a choir may cause severe difficulties. 
The frequency range of Ave Maria is only 13 semitones. In these recordings, the intensity and tempo levels as well as the variations in these parameters were moderate. These circumstances suggest that the singers were singing in ranges which they felt as comfortable with respect to frequency, intensity, and tempo; hence, no measurements should reflect extreme vocal conditions for the singers.

Only those tones were selected for analysis, that were long enough to provide relevant data. These
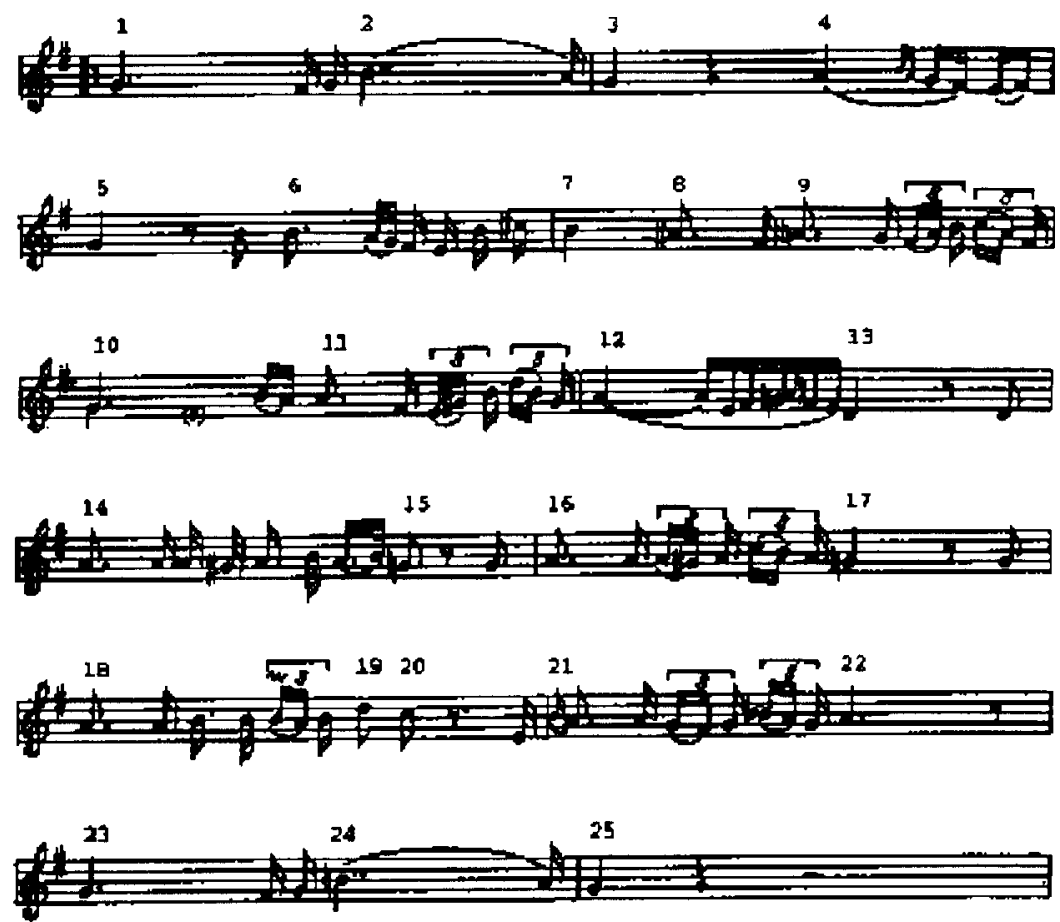

Fig. 1. The music score of Franz Schubert's Ave Maria. The notes selected for measurements are numbered 1 to 25.

tones are shown in Fig. 1, numbered in consecutive order (1-25).

\section{Measurement procedure}

Measurements were made on time spectrograms as displayed on a KAY DSP Sonagraph, Model $5500^{1}$. The time from one wave-trough to the next was measured. Such

\begin{tabular}{|c|l|l|c|l|c|c|}
\hline Artist: & $\begin{array}{c}\text { Voice } \\
\text { Classific. }\end{array}$ & Language & $\begin{array}{c}\text { Number of } \\
\text { stanzas }\end{array}$ & Accomp. & $\begin{array}{c}\text { Recording } \\
\text { year }\end{array}$ & $\begin{array}{c}\text { Age of } \\
\text { artist }\end{array}$ \\
\hline 1 & Soprano & German & 2 & Piano & 1975 & 37 \\
\hline 2 & Soprano & German & 3 & Orchestra & 1990 & 42 \\
\hline 3 & Soprano & Latin & 2 & Harp & 1984 & 41 \\
\hline 4 & Soprano & German & 3 & Piano & 1988 & 41 \\
\hline 5 & Soprano & German & 3 & Piano & 1971 & 26 \\
\hline 6 & Mezzo & German & 2 & Piano & 1936 & 34 \\
\hline 7 & Alto & German & 3 & Piano & 1971 & 38 \\
\hline 8 & Tenor & German & 1 & Orchestra & 1979 & 38 \\
\hline 9 & Tenor & Latin & 2 & Organ/Choir & 1968 & 35 \\
\hline 10 & Tenor & Latin & 2 & Piano & 1987 & 52 \\
\hline
\end{tabular}

Table I: The ten artists singing Ave Maria by Schubert.

a measurement can be made with an accuracy of about \pm 6 ms which means $5 \%$ of the resulting vibrato rate, approximately. A sequence of vibrato cycles would still have the same accuracy of $\pm 6 \mathrm{~ms}$ as the positions of the two cursors were alternated from wave-trough to wave-trough.

1Set-up: Frequency range: DC-8kHz, Analysis format: Spectrographic, Transform size: 1024 pts. $(29 \mathrm{~Hz})$, Analysis Window: Hamming, and Time axis: $100 \mathrm{~ms}(2 \mathrm{~s})$. 
To check the reliability of the method just described, Johan Liljencrants (of this department) measured the vibrato rate of one of the artists (\# 8) using a completely different method: "The computerized measurements of the vibrato were performed with a set of house developed programs for the Apollo workstation. Initially the recording was highpass filtered with $30 \mathrm{~dB} /$ oct Butterworth filter at $1.5 \mathrm{kHz}$ to enhance the singing formant range over the orchestral accompaniment. Then the pitch was coarsely measured using cepstrum analysis followed by fine adjustment based on the several harmonic peaks detected in the spectrum. The pitch measurement file, sampled at $200 \mathrm{~Hz}$ was then hand edited such that irrelevant portions where the singer paused or the measurement was corrupted by interference were replaced by straight lines. This wave form (Fig. 2, top trace) was then highpass filtered with a similar filter as above, but using $3 \mathrm{~Hz}$ cut-off, zero phase, (Fig. 2, mid trace). The result contains only the variations in pitch and its periodicity was determined with the AMDF method (Absolute Minimum Difference Function) to render the vibrato period, displayed as frequency in Fig. 2, bottom trace. This was hand edited to clear spurious points." (Liljencrants, personal communication).

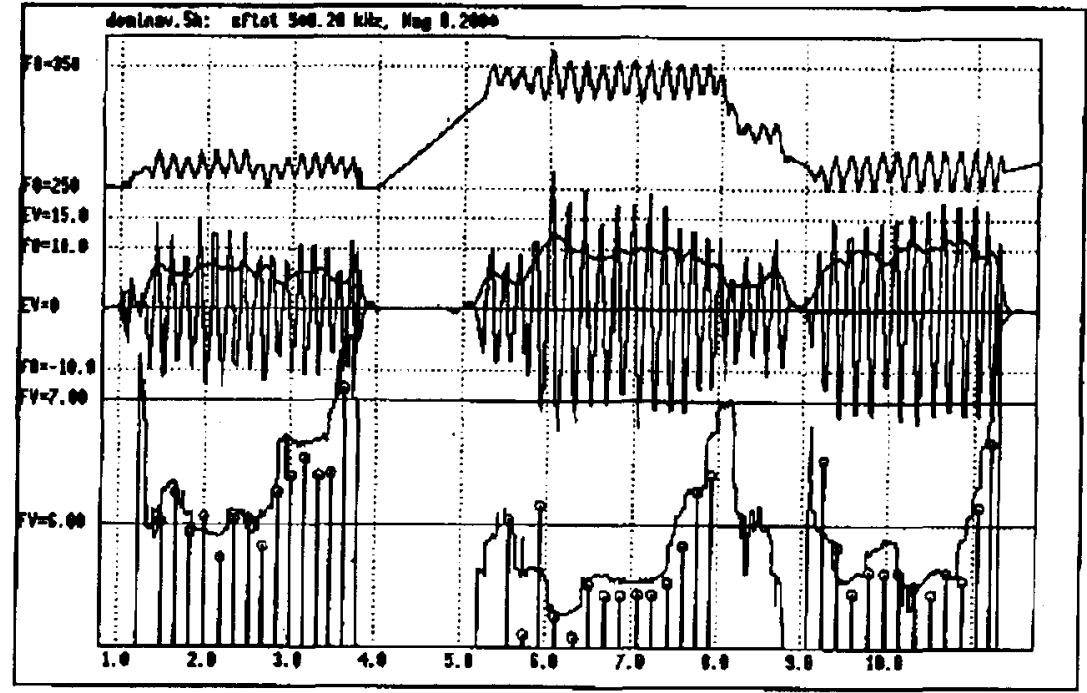

Fig. 2. An example of computer analysis of the vibrato rate of the three first notes of artist \#8, made by Johan Liljencrants. The pitch is shown in the top trace, the vibrato in the mid trace, and the vibrato rate in the bottom trace. The values obtained by the Sona-graph are inserted for comparison as circles on bars in the bottom trace.
Fig. 2 shows an example of his analysis of the three first notes of artist \# 8. My measured values (see Fig. 3) have been inserted into the bottom trace of Fig. 2 as circles on bars. The degree of consistency between the two methods turned out to be surprisingly high.

It proved to be difficult to identify the first clear wave-trough of a tone in many cases. The problem was circumvented by accepting even a faint indication of the first vibrato cycle and then omitting this first vibrato cycle from the subsequent calculation of average rate values (see below). In some cases, the intensity at the end of certain tones, typically occurring before a rest, was too low to allow measurement of vibrato rate; hence, these tones were excluded from the calculation of averages.

\section{RESULTS}

\section{Intra-tone aspect}

All vibrato cycles for the 25 notes were measured for all artists. Fig. 3 shows the measurements of artist \# 8. Here also the very first cycle of each note is included. With regard to the tones' head (beginning), body, and tail (ending), three observations can be made: 
1. the cycles pertaining to the head do not show any typical structure and do not deviate in any obvious way from the following cycles,

2 . the tail, by contrast, has a very typical increase in vibrato rate during the last 1-4 cycles, and

3. the cycle-to-cycle variation of the body is moderate.

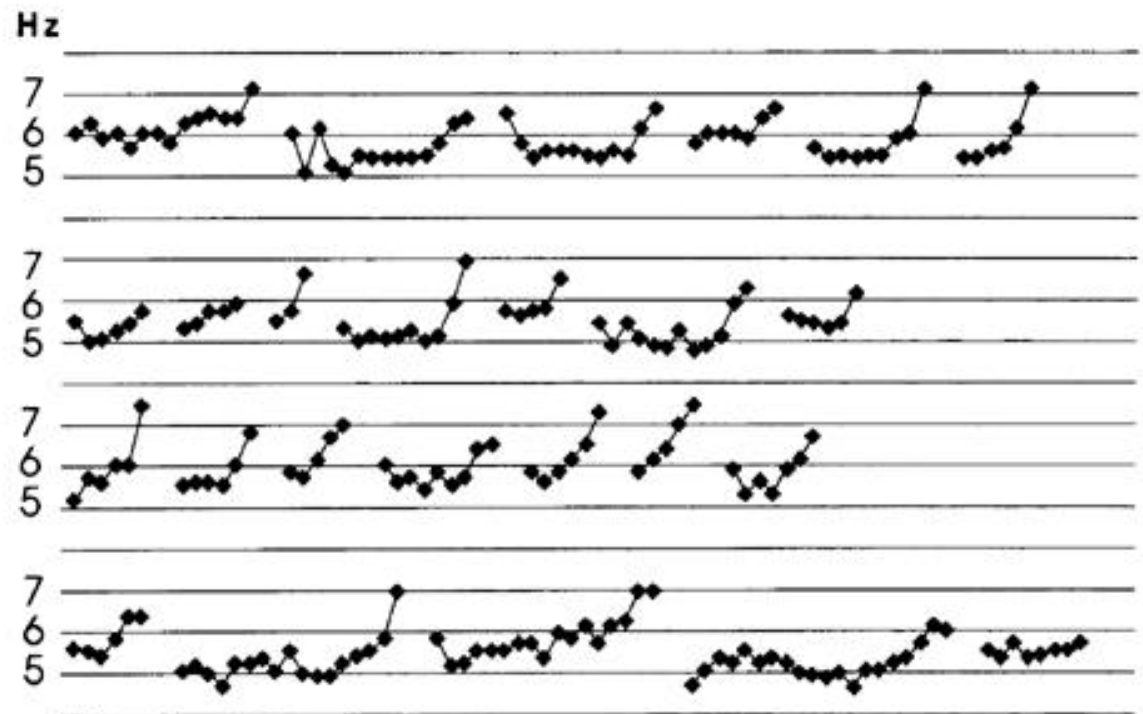

Fig. 3. The vibrato rate of each vibrato cycle of the 25 tones of singer $\# 8$.

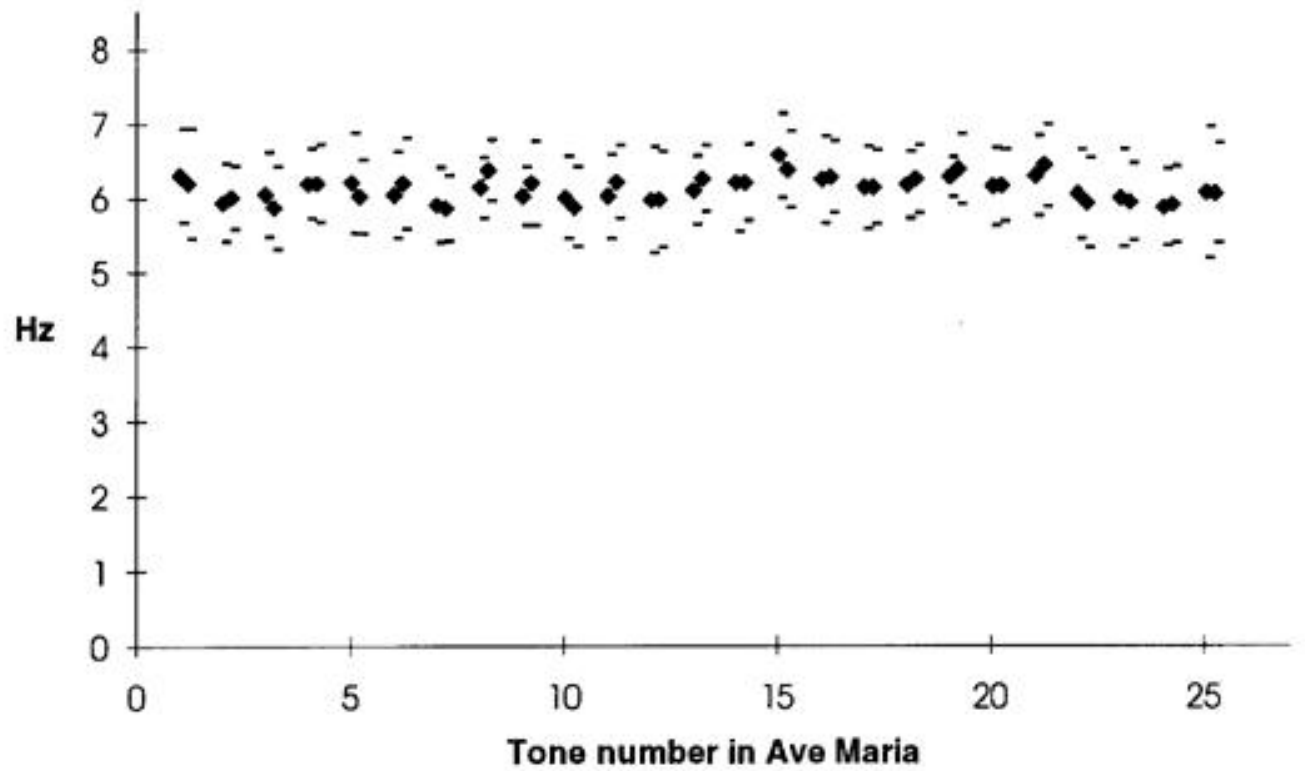

Fig. 4. The average vibrato rates and SD of the 2 nd and $3 r d$ vibrato cycles for the 25 tones in the performances of all 10 singers.

The first two observations seem applicable to most artists, as can be seen in Figs. 4-5. Fig. 4 shows the average rates of the second and third vibrato cycles for all 25 tones in the performances of all tone artists. Fig. 5 shows the corresponding data for the four tone-final cycles. Without exception, each tone showed a clearly increasing 
average vibrato rate in the tail. However, this pattern was not observed in each individual tone of each individual artist.
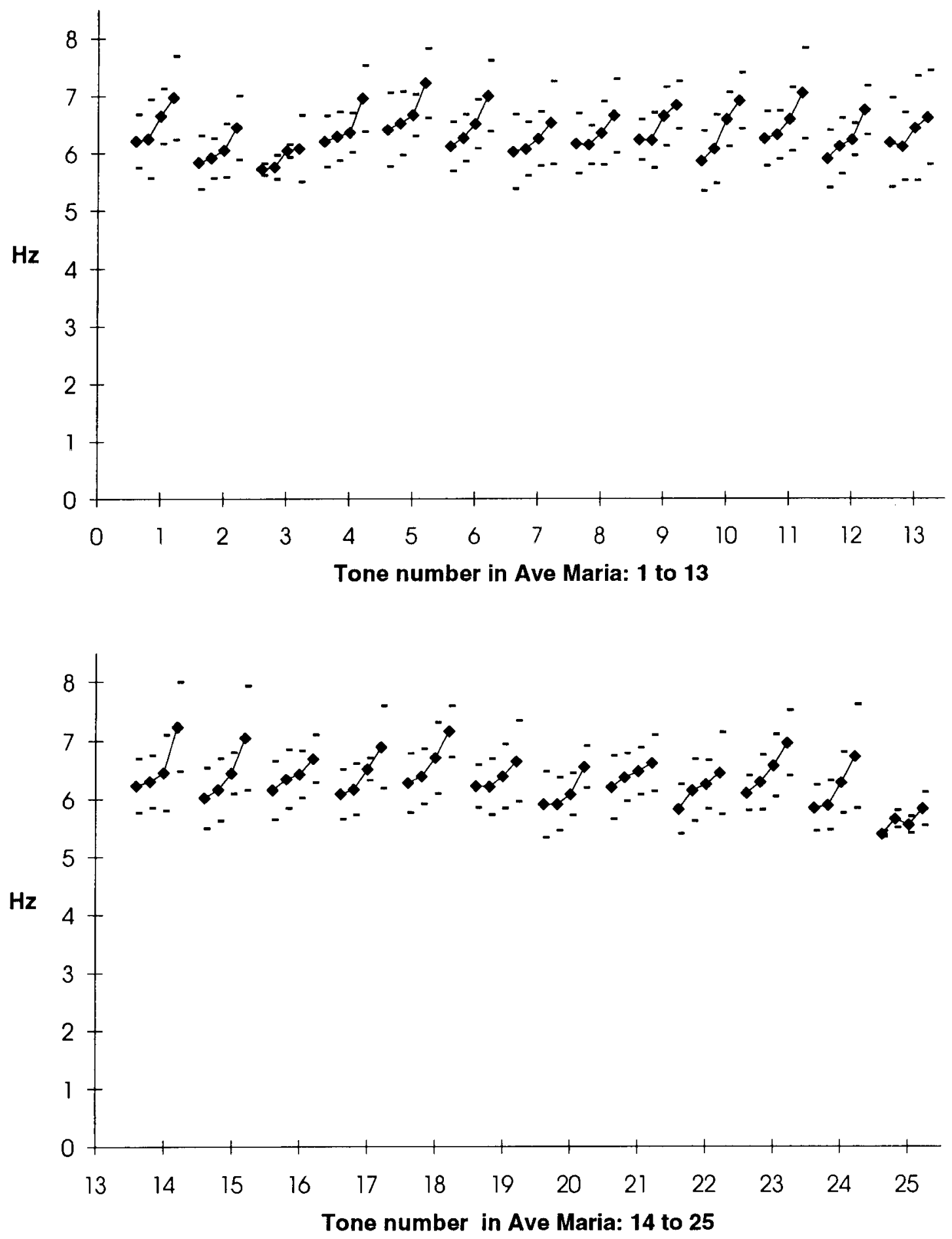

Fig. 5. The average vibrato rates and SD of the 4 tone-final vibrato cycles for the 25 tones in the performances of all ten singers.

This somewhat unexpected finding raised the question whether or not this characteristic increase of the vibrato rate was specific to singing only. To investigate this, four recordings, one played on a cello and three on violins, of the same composition 
Ave Maria were analyzed by the same procedure as for the vocal performances. The same ending pattern was found, as illustrated in Fig. 6, which shows the mean and the standard deviation (SD) for the vibrato rate of the last four cycles of all 25 tones as performed by the ten singers, the cellist, and the three violinists.

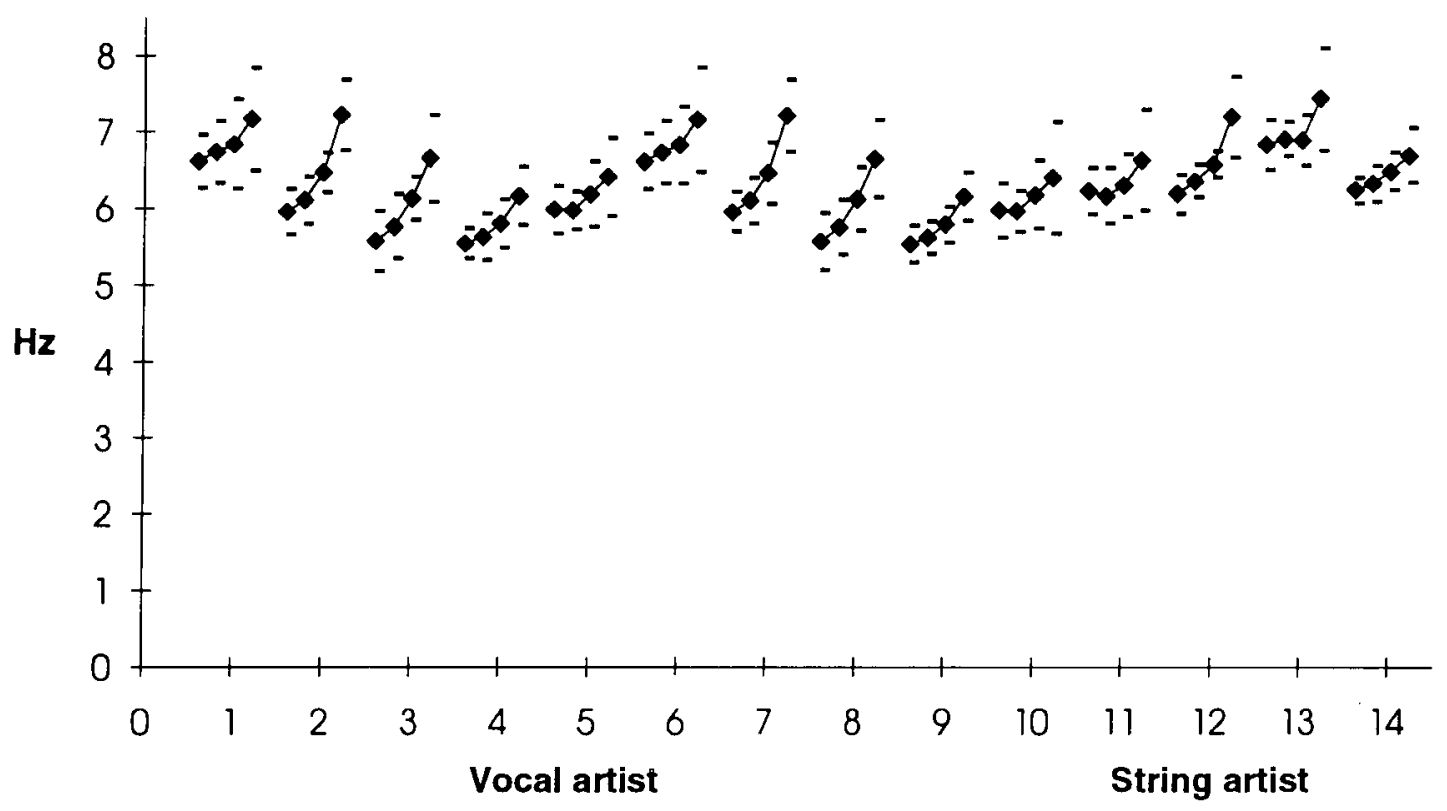

Fig. 6. The average and SD for the vibrato rate of the last 4 cycles of all 25 tones as performed by ten singers, one cellist, and three violinists.

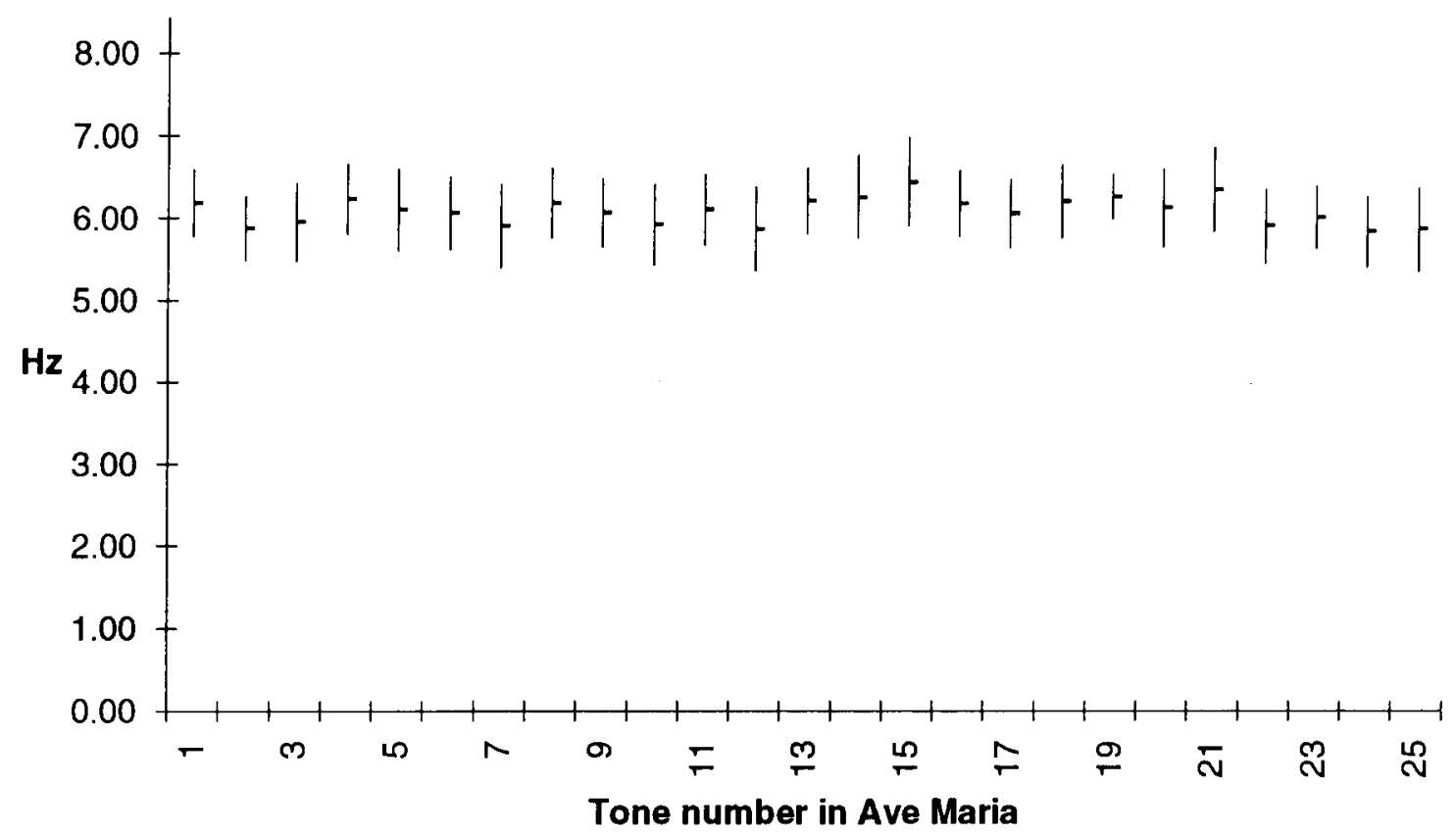

Fig. 7.

Even if Fig. 3 suggested that the cycle-to-cycle variation in the body was moderate, an informal analysis of the entire material revealed variations from tone to tone with respect to the degree of the cycle-to-cycle variation. For instance, the very first tone of the piece had, on the average, the highest degree of cycle-to-cycle variation. 
According to Seashore (1936, Ch. 8), Bjørklund (1961), and Schultz-Coulon \& Battmer (1981), the cycle-to-cycle variation decreases with training. It seems likely that the cycle-to-cycle variation relates to the mechanism of vibrato control. Seashore mentions $0.5 \mathrm{~Hz}$ as a typical average for this variation. Hakes, \& al (1987) found an average vibrato jitter of $13.7 \%$ over ten singers of early music. As the cycle-to-cycle variation of the vibrato rate is probably coupled to those of the vibrato extent and the vibrato waveform, we shall deal with this subject in a later study.

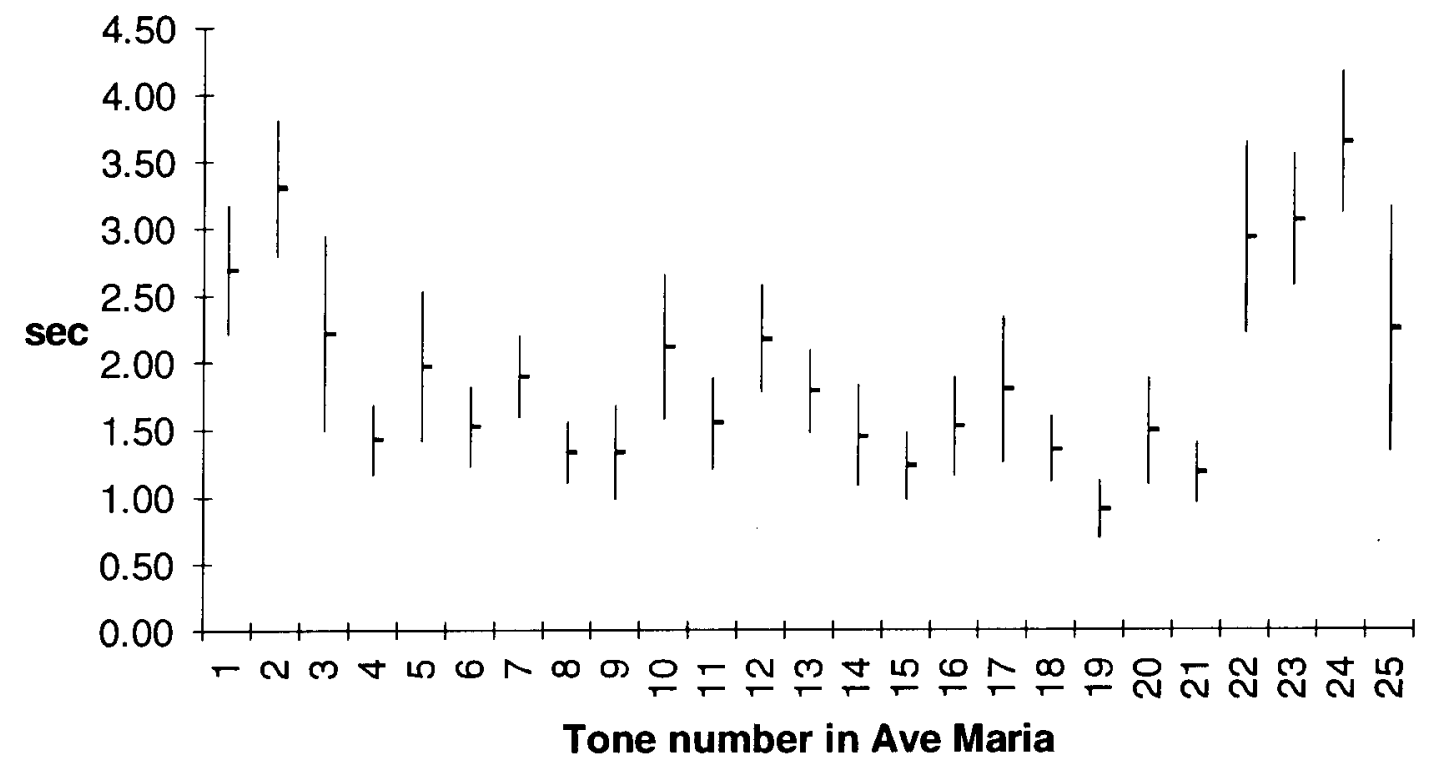

Fig. 8. Tone duration averages and SD of the 10 singers for the 25 tones.

\section{Inter-tone aspect}

For each tone, the very first vibrato cycle was omitted in the calculation of the average vibrato rate, as mentioned. In addition, we also omitted the last three vibrato cycles because of the ending pattern discussed above. To increase the statistical material as much as possible, we included in the averages all notes containing at least one vibrato cycle, disregarding head and tail. This means that when calculating average vibrato rates for a specific tone across different artists, the data generally reflect a number of vibrato cycles, but in exceptional cases, the data may pertain to one single vibrato cycle only.

The average rate over the ten artists were calculated for each of the 25 tones, see Fig. 7. The average is in the vicinity of $6 \mathrm{~Hz}$ and the variability is moderate. However, a negative correlation $(\rho=-0.69)$ was observed with the average tone duration (see Fig. 8), such that the shorter tones tended to show slightly higher vibrato rates than longer tones. This is illustrated in Fig. 9 which shows the vibrato rate as a function of tone duration. However, the correlation for each artist between the average vibrato rate and duration for a tone varied between -0.1 to -0.71 with an average value of -0.42 (Table II). Therefore, even if there was a correlation between the two parameters as an average over this group of artists, no conclusions can be drawn as to the behaviour of a particular artist. 


\begin{tabular}{|c|c|c|c|c|c|c|c|c|}
\hline artist & $\begin{array}{c}\text { vibrato rate } \\
\text { average }\end{array}$ & $\begin{array}{c}\text { standard } \\
\text { deviation }\end{array}$ & $\begin{array}{c}\text { maximum } \\
\text { rate }\end{array}$ & $\begin{array}{c}\text { minimum } \\
\text { rate }\end{array}$ & $\begin{array}{c}\text { variation } \\
\text { index }\end{array}$ & $\begin{array}{c}\text { end quotient } \\
* *\end{array}$ & $\begin{array}{c}\text { tempo } \\
\text { rate/duration }\end{array}$ \\
\hline & $\mathrm{Hz}$ & $\mathrm{Hz}$ & $\mathrm{Hz}$ & $\mathrm{Hz}$ & & & 44 th time & $\mathrm{r}$ \\
\hline 1 & 5.8 & 0.37 & 6.2 & 5.4 & 0.15 & 1.16 & 30.8 & -0.71 \\
\hline 2 & 6.5 & 0.25 & 6.7 & 6.0 & 0.12 & 1.09 & 27.6 & -0.36 \\
\hline 3 & 6.5 & 0.29 & 7.1 & 5.8 & 0.20 & 1.11 & 33.3 & -0.44 \\
\hline 4 & 6.2 & 0.27 & 6.4 & 5.5 & 0.15 & 1.13 & 28.2 & -0.57 \\
\hline 5 & 6.1 & 0.22 & 6.3 & 5.4 & 0.15 & 1.08 & 28.6 & -0.49 \\
\hline 6 & 6.6 & 0.25 & 7.3 & 6.0 & 0.21 & 1.08 & 20.0 & -0.26 \\
\hline 7 & 6.0 & 0.37 & 6.9 & 5.4 & 0.25 & 1.21 & 25.8 & -0.10 \\
\hline 8 & 5.5 & 0.30 & 6.4 & 5.0 & 0.26 & 1.20 & 28.6 & -0.42 \\
\hline 9 & 5.5 & 0.12 & 5.7 & 5.2 & 0.10 & 1.11 & 28.2 & -0.20 \\
\hline 10 & 5.9 & 0.27 & 6.5 & 5.4 & 0.19 & 1.07 & 23.8 & -0.62 \\
\hline max. value & 6.6 & 0.37 & 7.3 & 6.0 & 0.26 & 1.21 & 33.3 & -0.10 \\
\hline aver. value & 6.1 & 0.27 & 6.6 & 5.5 & 0.18 & 1.13 & 27.5 & -0.42 \\
\hline min. value & 5.5 & 0.12 & 5.7 & 5.0 & 0.10 & 1.07 & 20.0 & -0.71 \\
\hline
\end{tabular}

*the difference between the maximum and minimum rates divided with the geometric means of these rates

**the quotient between an artist's rates of the last vibrato period in the tones and the fourth period from the end

Table II: Various measurements for the 10 singers. 


\section{Characteristics of the artists}

Various values related to the ten artists are listed in Table II. For the body of the investigated tones, the average vibrato rate and SD were calculated for each artist. The three consecutive cycles in any tone of an artist giving the maximum average rate and the minimum average rate, respectively, have also been measured. The following column shows a variation index based upon the content of the preceding two columns: the difference between the max. and min. values divided by the geometric means of those values. The next column shows the quotient between an artist's last vibrato period and the fourth period from the end (see Fig. 6) The tempo (in four fourths time) has been measured and finally the correlations between vibrato rate and the tone duration are shown.

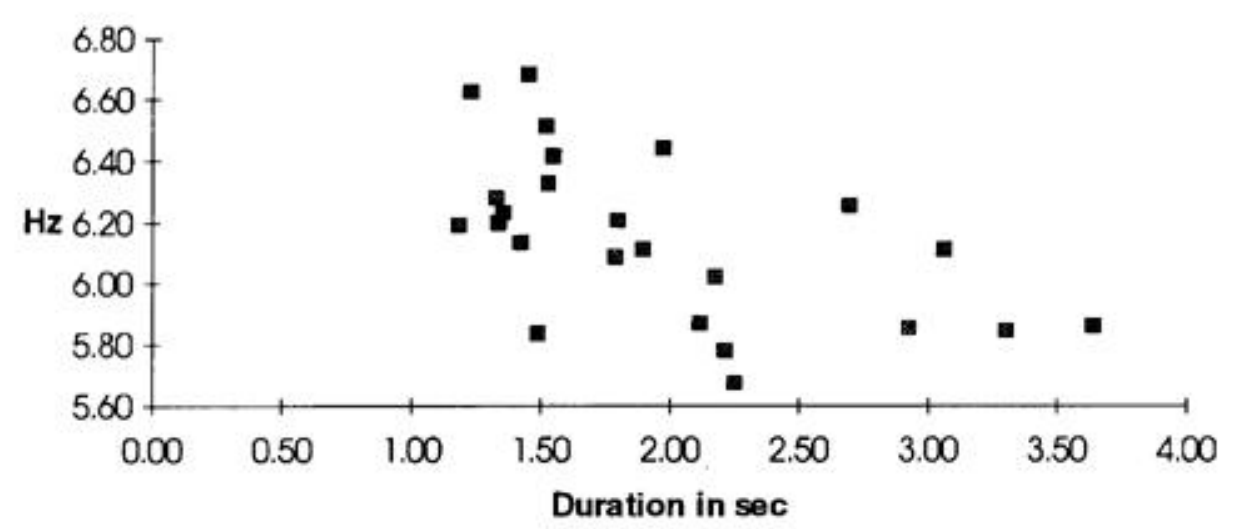

Fig. 9. The correlation between vibrato rate and tone duration for the 25 tones. Each point represents the average over the 10 singers.

As shown in Table II, the rate averaged across all ten artists is $6.1 \mathrm{~Hz}$ with extremes at 5.0 and $7.3 \mathrm{~Hz}$. The vibrato rate at the tail increased by $+13 \%$, on the average. We can, furthermore, observe that the averages of all singers' maximum and minimum rates in the song were 6.6 and $5.5 \mathrm{~Hz}$, respectively.

\section{DISCUSSION}

The ending structure of a tone and the definition of average vibrato

One of the main results of the present investigation was the increase of the vibrato rate toward the end of the tones, regardless of whether or not the tone is followed by a rest, see Figs. 3, 5, and 6. This phenomenon was observed in both vocal and string performances. This poses the question what the origin can be. The mechanism producing the vibrato is completely different in singing and in bowed instrument playing. Therefore, the answer must either be sought in the very basic neuro-physiological behaviour of the muscle activity in the performer or, at the other extreme, in the demands on musical performance raised by the perceptual system or by conventions.

Vennard (1967) stated that a "good singer sets the tempo in multiples of his vibrato; if the tone cannot be shortened/prolonged, a good singer slows or speeds his vibrato to conform to the duration of the tone." d'Allessandro \& Castellengo (1991) observed that frequency changes between the scale tones tend to be timed in such a manner that the change happens in phase with the vibrato, i.e., as a prolongation of 
the frequency change due to the vibrato. This may lead to the assumption that (1) the vibrato rate is changed during the end of the tone, such that the pitch change happens in phase with the vibrato and (2) that for one or another reason, a speeding up of the vibrato rate is easier to perform than a slowing down; almost no example was found of a slowing down during the end of a tone. This would imply that tones followed by a rest should not exhibit the typical ending structure. Fig. 1 shows that the tones $3,5,13,15,17,20,22$, and 25 all are followed by a rest, while the remaining tones are followed by another tone. However, Fig. 5 shows no typical ending-structure difference depending on the note's location in the music score. Thus, the tendency to synchronize the pitch changes with the vibrato does not seem to explain the speeding up of the vibrato toward the end of the tones.

Even if it is difficult now to realize an explanation to the ending structure, this structure in itself partially explains the confusion regarding the vibrato rate in the past. As the vibrato rate tends to increase during the last three vibrato cycles of a tone, the average the vibrato rate of a tone will depend on its duration, shorter tones showing higher average rates than longer tones. In addition, a slight dependence ( $\rho$ $=-0.69$ ) on the tone duration was found even when the three last vibrato cycles were eliminated. As Seashore strived for including all tones in the pieces he analyzed, his material contained a relatively high percentage of short tones. Furthermore, he included all the vibrato cycles in each tone when calculating the average vibrato rate for an artist. For this reason, he arrived at rather high values of the vibrato rate. Shipp, \& al. (1980), by contrast, had singer subjects to produce tones of 4-14 sec duration and cut out a 1-sec long segment from the middle of these tones. Taking into account the above results. it is not surprising that Shipp, \& al. obtained much lower averages than Seashore.

As a practical consequence of the above, the last three vibrato cycles should be excluded in the calculations of the average vibrato rate for an artist. Such an average is, however, still influenced by the slight negative dependence of the vibrato rate on the tone duration. The average rate, obtained for a given artist from measurements on a given piece of music will then be influenced by the mix of long and short notes that were included in the study. Consequently, it does not seem meaningful to define a general vibrato rate for an artist, while specific average vibrato rates for different artists can still be used, e.g., for the purpose of comparison, provided they are based on the same material of tones.

The slight dependence of the vibrato rate on the tone duration may be due to the fact that in the calculation of the mean vibrato rate we only eliminated the three final vibrato cycles of the tones. It cannot be excluded that the increase of the vibrato rate toward the end of a tone tends, on the average, to embrace a longer chain of vibrato cycles than the final three. This question should be further investigated in the future.

Which other parameters may have been influential on the vibrato rate values shown in Fig. 7? Correlations with musical context parameters were not analyzed but cannot be excluded. Seashore (1936, Ch. 8) observed a slight pitch dependence for high pitches. No pitch dependence was found in the present investigation. However, the frequency range of the Ave Maria amounted to no more than 13 semitones and in the recordings analyzed, the range was apparently chosen so as to be comfortable for the singers. A correlation between the vibrato rate and the extent or with the vocal loudness should be tested in the future. 


\section{The rate values per artist}

The lowest vibrato rate found in this study was $5.0 \mathrm{~Hz}$ (Table II column 5). According to Seashore (1936, Ch. 8), the lower limit for the rate of what normally is considered as a vibrato is the "point at which a steady quality of tone enters and wobbliness ceases so that the pulsation begins to fuse, is not a sharp point, but varies for different listeners, different singers, and other variables in tone." This point appears to lie somewhere between 4.5 and $5.0 \mathrm{~Hz}$. However, some values deviating considerably from these rates occur. For example, in Verdi's Macbeth (Act 4: "Una macchia è quì tuttora!", the second note from the end) ${ }^{2}$ Maria Callas produced three consecutive vibrato periods with an average rate of no more than $4.1 \mathrm{~Hz}$, which, if listened to in isolation, certainly does not sound as an acceptable vibrato. Moreover, in the last note of the same aria, there are three cycles with an average value of 6.2 $\mathrm{Hz}$. This yields a variation index of 0.42 , which is considerable higher than any artist in the present study (see Table II). Some of this variability can probably be attributed to Callas' extreme expressiveness, but it is likely that the more dramatic piece of music like this Verdi aria contributed to the difference in the variation indices. According to Vennard (1967), "usually the same singer's rate decreases in concert where he does not have to compete in volume with a sixty-piece orchestra." The question whether the same artist uses different vibrato rates for singing different types of music and in different musical settings should be addressed in a future study.

The seven female and the three male singers had the average vibrato rates of 6.3 $\mathrm{Hz}$ and $5.7 \mathrm{~Hz}$, respectively. From a statistical point of view, these numbers of subjects are obviously too low to allow any conclusion. Still, it is interesting to note, that even though Seashore (1936, Ch. 8) did not observe any gender-related difference in the vibrato rate, Shipp, \& al. (1980) in their study of female and male singers found an average rate of $5.9 \mathrm{~Hz}$ and $5.4 \mathrm{~Hz}$, respectively, for their five female and five male subjects.

\section{How constant is the vibrato rate?}

The maximum and minimum vibrato rates for the singers were defined as the highest and lowest means of three consecutive vibrato cycles in order to reduce the risk of getting extreme values. If we had based these extremes on single vibrato cycles and included the tails, instead, artist \# 8 would have had a range of $4.6 \mathrm{~Hz}$ to $7.4 \mathrm{~Hz}$, see Fig. 3; the range of all artists would have been between $4.6 \mathrm{~Hz}$ and $8.7 \mathrm{~Hz}$.

Sundberg (1987) remarked that "the rate of the frequency modulation is generally considered to be constant within a singer; that is, the singer is usually unable to change it." Disregarding the cycle-to-cycle variation in the body of the tone, our findings show that this statement should be modified:

- the rate tends to increase by about $13 \%$ on the average toward the end of the tone, and

- the inter-tone variation between the (3-cycle) maximum and minimum for an artist is about $\pm 10 \%$ of the personal average.

The total variation between the artists' averages was found to be about $\pm 10 \%$ of the group mean, i.e., quite similar to the inter-tone variation.

${ }^{2}$ CDC 747730 2, originally recorded in 1959. 


\section{CONCLUSIONS}

The vibrato rate tends to increase according to a typical pattern covering the last vibrato cycles of a tone both in vocal and bowed instrument performance. This average pattern was observed for all 25 notes analyzed, although the pattern was not necessarily found in each single tone of each single artist. No typical vibrato pattern could be observed in the beginning of the tones. The average vibrato rate tended to decrease slightly with the tone duration. As a consequence, the representativity of previously reported averages of the vibrato rate may be somewhat limited.

If the increase of the vibrato rate toward the tone endings is disregarded, the mean rate across the singers was $6.1 \mathrm{~Hz}$. The average variation between maximum and minimum rate within an artist is about $\pm 10 \%$ of the artist average. The variation across the artists between the maximum and minimum personal mean rate was also about $\pm 10 \%$ of the group average.

\section{ACKNOWLEDGEMENTS}

I would like to thank Johan Sundberg and Johan Liljencrants for many helpful and stimulating discussions and Johan Sundberg also for assistance in preparing this manuscript.

\section{REFERENCES}

d'Alessandro, C. \& Castellengo, M. (1991): "Etude, par la synthese, de la perception du vibrato vocal dans les transition de notes," Bull. d'Audiophonologie, Ann. Sc. Univ. FrancheComté 7, pp. 551-564.

Bjørklund, A. (1961): "Analysis of soprano voices," J.Acoust.Soc.Am. 33, pp. 575-582.

Hakes, J., Shipp, T., \& Doherty, T. (1987): "Acoustic characteristics of vocal oscillations: vibrato, exaggerated vibrato, trill, and trillo," J.Voice 1, pp. 326-331.

Horii, Y. (1989): "Acoustic analysis of vocal vibrato: a theoretical interpretation of data," J.Voice 3, pp. 36-43.

Meyer, J. (1991): "Die spektrale Feinstruktur von Vibratoklängen," pp. 285-290 in Proc. of the 9th FASE Symp. and the 10th Hungarian Conf. on Acoustics, Balatonfüred, May 7-9, 1991, Hungary.

Rothenberg, M., Miller, D., \& Molitor, R. (1988): "Aerodynamic investigation of sources of vibrato," Folia Phoniat. 40, pp. 244-260.

Schultz-Coulon, H.J. \& Battmer, R-D. (1981): "Die quantitative Bewertung des Sängervibratos," Folia Phoniat. 33, pp. 1-14.

Seashore, C.E. (Ed.) (1932): "The vibrato," Univ. of Iowa Studies in the Psychology of Music, Vd. I.

Seashore, C.E. (1936): "Psychology of the vibrato in voice and instrument," Univ. of lowa Studies in the Psychology of Music, Vol. III.

Seashore, C.E. (Ed.) (1937): "Objective analysis of musical performance," Univ. of Iowa Studies in the Psychology of Music, Vol. IV.

Seashore, C.E. (1938): Psychology of Music, McGraw-Hill, New York (Reprint: Dover, New York, 1967.

Shipp, T, Leanderson, R., \& Sundberg, J. (1980): "Some acoustic characteristics of vocal vibrato," J.Res. in Sing. IV:1, pp. 18-25. 
Shipp, T., Sundberg, J., \& Haglund, S. (1984): "A model of frequency vibrato," pp. 116-117 in (L. van Lawrence, Ed.) Transcripts of the 13th Symposium Care of the Professional Voice, New Voice Foundation, New York.

Shipp, T., Doherty, T., \& Haglund, S. (1990): "Physiologic factors in vocal vibrato production," J.Voice 4, pp. 300-304.

Sundberg, J. (1982): "Perception of singing," pp. 83-84 in (Deutsch, D., Ed.) The Psychology of Music, Academic Press, New York.

Sundberg, J. (1987): The Science of the Singing Voice, Northern Illinois University Press, p. 163. Vennard, W. (1967): Singing, the Mechanism and the Technic, (2nd ed.) Fischer, New York, pp. 192-208. 